\title{
Diet, Smoking and Family History as Potential Risk Factors in Acne Vulgaris - a Community-Based Study
}

\author{
Al Hussein Stela Mariana ${ }^{1}$, Al Hussein Hussam²*, Vari Camil Eugen³, Todoran Nicoleta1 ${ }^{1}$, Al Hussein \\ Hamida$^{2}$, Ciurba Adriana ${ }^{1}$, Dogaru Maria Titica ${ }^{3}$ \\ 1 Faculty of Pharmacy, Department of Pharmaceutical Technology, Dermopharmacy and Cosmetology, University of Medicine and Pharmacy of Tîrgu Mureș, \\ Romania \\ 2 Faculty of Medicine, Student, University of Medicine and Pharmacy of Tîrgu Mureș, Romania \\ 3 Faculty of Pharmacy, Department of Pharmacology and Clinical Pharmacy, University of Medicine and Pharmacy of Tîrgu Mureș, Romania
}

Objective. This study aimed to evaluate the effects of practices and attitudes towards lifestyle in adolescence as risk or protective factors, for both the acne occurrence and lesions' severity.

Methods. A cross-sectional study based on a self-reported questionnaire was conducted during 4 months on 148 high school students, aged 16-20 years, in a high school community of Tîrgu Mureș. Acne prevalence and severity, demographic and anthropometric characteristics, the family history of acne vulgaris, smoking behavior and the weekly intake of certain food categories supposed to increase the risk of acne vulgaris were evaluated. Statistical analysis was performed in terms of Odds ratio, Confidence Interval and Chi-square ( $<<0.05)$ methods. Results. In the investigated community, acne prevalence was found of $47.30 \%$, while 78 subjects (control group) had no facial acne lesions. In acne group: $57.1 \%$ had family history of acne, $62.9 \%$ were smokers, $22.9 \%$ were overweight or obese and $84.3 \%$ did not receive any dietary information from specialists. $41.4 \%$ were not fish consumers, while $74.3 \%$ rarely or never were eating fruits and vegetables. Statistically significant differences between the two analyzed groups were found in terms of sweets, carbonated drinks, dietary fat, white bread, fish, fruits and vegetables weekly intake.

Conclusions. Family history, smoking behavior, excessive dietary fat, sweets, carbonated drinks and white bread could be considered as risk factors in acne vulgaris. An increased weekly intake of fish, vegetables and fruits, may have a protective effect in acne development or severity.

Keywords: acne vulgaris, diet, smoking, family history, risk factors

Received: 22 November 2015 / Accepted: 05 January 2016

\section{Introduction}

Considering the well-accepted fact that acne vulgaris is a chronic and multifactorial skin disease, which can persist into adulthood, with negative effects on self-esteem, the specialists are constantly looking for adjunctive therapies that could help improve the quality of life of acne patients. Although there is no any ideal treatment of acne, most patients can find an appropriate treatment to reduce the acne lesions $[1,2]$.

Since the 1800s and early 1900s, many dermatology manuals have often recommended the diet as an adjunctive method in the treatment of various skin diseases. Therefore, as $32 \%$ of respondents chose their diet as the primary cause, and $44 \%$ just had thought that the food would may aggravate the acne, Tan et al found, in 2001, that diet, in perception of the questioned patients, is considered the third most common factor (after hormones and genetics) causing the disease [3]. According with the investigations performed to date, the most incriminated food categories were milk and dairy products, dietary fats and sweets, or generally speaking high glycemic load food.

Milk usually contains growth stimulation hormones [4], progesterone secreted by placenta and other precursors of dihydrotestosterone (DHT), including 5 $\alpha$-pregnanedion

* Correspondence to: Hussam Al Hussein

E-mail: alhussein.hussam@yahoo.com and $5 \alpha$-androstenedione. These compounds are enzymatically converted to DHT, the main acne stimulator, the mediating enzymes for these changes being present in human pilosebaceous unit [5]. Insulin-like growth factor (IGF-1) present in ordinary milk is the most likely candidate responsible for pilosebaceous unit function or dysfunction by costimulation with steroid hormones. IGF-1 stimulates the androgens synthesis in the ovary, adrenal glands and testes. Has been shown that insulin and especially IGF-1 stimulate follicle growth and sebocytes $[6,7]$. Therefore, between blood IGF-1 levels in prepubertal, pubertal, adolescence, young adulthood, and prevalence curve of acne, is a clear similarity [8]. It was hypothesized that dairy products increase the severity of acne by diet-induced hyperinsulinemia, increasing IGF-1 levels. A study published in 2005 enlighten that both whole milk and skimmed milk, but not cheese, have the glycemic load and insulinotropic response three to six times higher than that predictable - based on the carbohydrate content of the milk [9]. The comedogenic effect demonstrated for skim milk may be due to other components of milk, such as proteins. Whey protein and casein are the major milk proteins, having different effects: casein increases the IGF-1 levels, whereas whey protein is a pronounced inducer of postprandial hyperinsulinemia $[10,11,12]$. Although there are no randomized controlled trials to examine the relationship between dairy products, milk or milk proteins and the cellular signaling pathway, 
there is a theory which suggests that the whey protein, rich in leucine, exacerbate the acne by cell growth induction, androgens secretion and sebaceous lipogenesis stimulation [13]. A high glycemic load induces hyperinsulinemia, leading to an endocrine response that stimulates IGF-1 and, at the same time, suppresses the insulin-like growth factorbinding protein 3 (IGFBP-3). In addition, IGF-1 stimulates the sebum production by enhancing sterol regulatory element-binding protein 1 (SREBP-1), which can further stimulate the lipogenesis in sebocytes through phosphoinositide 3-kinase activation [14,15]. Normally, IGFBP-3 and steroid hormone-binding protein (SHBP) function as inhibitors of binding molecules for IGF-1 and androgens. The IGFBP-3 and SHBP suppression induced by insulin results in an increased level of IGF-1 and androgens, thereby increasing acne severity [16]. This assumption is based on the evidence that IGF1 deficiency is associated with a decreased severity of acne [12,17]. IGFBP-3 reduction mediated by hyperinsulinemia induces acne development by stimulating follicle growth through retinoid signaling pathway. Specifically, IGFBP-3 is a ligand for the retinoic $\mathrm{X}$ alpha-receptor, and binding to this receptor leads to the inhibition of cell proliferation [18]. As a result, the low bioavailability of IGFBP-3 decreases the retinoic X alphareceptor activity, stimulating cell growth and acne development. Data from the literature about the dietary fat and carbohydrates effects on the sebum excretion and composition are confusing, contradictory and controversial. Several experimental studies, conducted on animals and human, have demonstrated that the high fat food or carbohydrates intake could affect the amount and the composition of excreted sebum [19]. Although the prevailing view is that the sebaceous glands synthesize their own lipids and do not take over the lipids from the circulation, the investigation conducted by Pappas et al in 2002 was the first one that followed the fate of exogenous fatty acids in human sebaceous glands [20]. This study suggests that the sebaceous glands are using the fatty acids from the blood circulation for the sebum synthesis [21]. In contrast, a relative intake of polyunsaturated $\omega-3$ and $\omega-6$ fatty acids is considered an important dietary modulator of inflammation. The $\omega-3$ polyunsaturated fatty acids may suppress the production of inflammatory cytokines by inhibiting the inflammatory leukotrienes B4 synthesis. Leukotrienes are synthesized mainly by the 5-lipoxygenase way and are associated with elevated inflammation markers and an increased severity of acne [22]. Administration of an 5-lipoxygenase inhibitor suppresses the leukotriene B4 concentration and reduces the inflammatory acne lesions, thus suggesting the therapeutic role of the unsaturated $\omega-3$ fatty acids in patients with acne [23]. In addition, the polyunsaturated $\omega-3$ fatty acids can reduce acne by decreasing the insulin and IGF-1 levels [24,25] and increasing IGFBP-3 concentration [26].

This study aimed to evaluate the effects of practices and attitudes towards lifestyle in adolescence as risk or protective factors, for both acne occurrence and lesions' severity.
Demographic and anthropometric characteristics, family history, smoking habits, and excessive intake of milk, yoghurt, dietary fat, sweets, carbonated drinks, white bread were analyzed as potential risk factors in development and exacerbation of acne vulgaris, while diets rich in fish, fruits and vegetable were analyzed as potential protective factors.

\section{Methods}

Community volunteers and conditions: The study was approved by the Research Ethics Committee of the University (no.99/2014), was performed during October 2014 to January 2015, and conducted as cross-sectional study based on a self-reported questionnaire (through interviewer's direct participation) on 148 high school students, aged 16-20 years, in a high school community of Tîrgu Mureș.

Self-reported questionnaire method and analyzed factors: The questionnaire was divided into several categories following issues of demographic data, anthropometric characteristics, family history of acne (mother or father), smoking behavior, the weekly intake of certain food categories: milk, yoghurt, cheese, sweets, dietary fats, white bread and whole-wheat bread, carbonated drinks, fish meat, fruits and vegetables, as well as dietary habits and the level of knowledge about the benefits of an adequate diet for a healthy skin.

Specialized clinical examination: Each student has been evaluated for acne vulgaris by the dermatologist and investigator, noting the presence or absence of facial acne lesions (inflammatory or non-inflammatory type). The degree of severity was established based on the total acne lesion count and the type of acne lesions, as follows: mild acne - subjects with less than 30 acne lesions on their face, including open and closed comedones; moderate acne - 30-50 acne lesions including papules and pustules; severe acne - more than 51 lesions including macrocysts and nodules.

Anthropometric measurements: were performed by determining the body weight and height. Body weight was measured using a digital scale Tanita HD-306 (Tanita Corporation, Japan). Height measurement was performed orthostatic, so that the heels, buttocks, and the upper part of the back reached the measuring scale and the head was positioned in the Frankfort plane. Body Mass Index (BMI) was calculated as the ratio between weight $(\mathrm{kg})$ and height squared $\left(\mathrm{m}^{2}\right)$.

Groups of the community adolescents: Data obtained from questionnaires were grouped by the variables category (as exposure factor) in two main groups: the control (no signs of lesions) and the acne group (mild acne and moderate/ severe acne as subgroups). In all cases, data were collected as number of cases (n) and then expressed as percentage to the total cases $(\mathrm{N})$ of the concerned group.

Statistical analysis: was performed by using the IBM Statistical Package for the Social Sciences SPSS 21 for OS X Program. Odds ratio (with 95\% confidence interval - CI) was calculated in order to determine if the exposure factor acts as risk (with high odds) or protective (with low odds) 
in acne development or its severity [27]. Chi-square test was applied to analyze the variance between the compared groups expressed by number of cases (statistical significance was set at $\mathrm{p}<0.05)$.

\section{Results}

A total number of 148 adolescents (110 male/38 female; mean age of $17.7 \pm 0.8$ years) were interviewed regarding their demographic data/their lifestyle practice, and then evaluated by a specialist examination. As has been shown in fig.1, based on the dermatologist evaluation: 78 students have been found without acne and they were considered healthy subjects (referred as control group); 70 students have been diagnosed with acne vulgaris (referred as acne group) in different stages of evolution, grouped and referred as: mild acne type (32 students) and moderate/severe acne type (38 students), respectively. (Figure 1)

Specific statistical parameters were calculated in order to quantify the degree of association between the analyzed lifestyle variables (as exposure factors) and the odds of acne development (Table I), or the odds of acne severity (Table II).

\section{Discussion}

\section{Comparative analysis of the results obtained by the study}

The influence of studied lifestyle factors on acne occurrence (Figure 2)

A family history of acne was more frequent among subjects belonging to acne group (57.14\%), than healthy subjects $(21.79 \%)$, as well as smoking behavior $(62.86 \%$, respectively $37.18 \%)$. The demographic data analysis showed that the majority of subjects from both groups were living in urban areas $(60.0 \%$ for acne group and $75.6 \%$ for control

\section{Acne prevalence / Community Studied}

Dermatologist clinical diagnosis

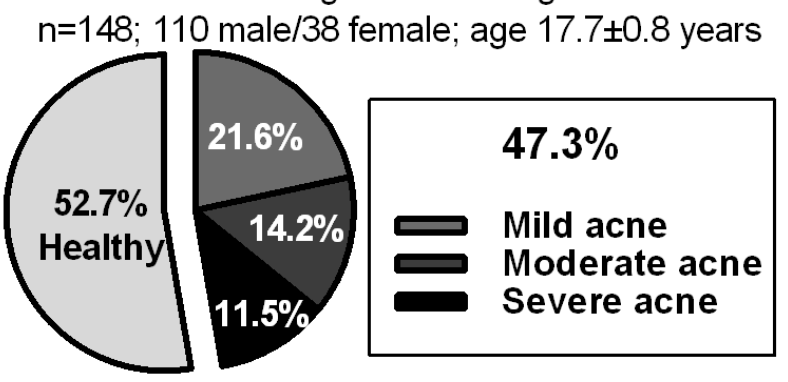

Fig. 1. Overall acne prevalence and prevalence according to severity

group). Anthropometric data analysis showed that $22.9 \%$ of acne subjects were overweight or obese (BMI $=25.0-29.9$ - overweight; $B M I \geq 30$ - obese), while only $6.4 \% \quad(n=5)$ from healthy subjects were included in this category. Statistical analysis demonstrated a significant difference between acne group and control group for family history, smoking habits, an overweight/obese condition; considering OR and $\mathrm{CI}$ values, these variables have been shown to be risk factors for acne vulgaris development. Despite a significant difference noticed for living environment $(\mathrm{p}=0.041)$, according with OR and CI values, living in urban areas did not represent a risk factor for acne occurrence.

The influence of studied dietary risk factors on acne occurrence (Figure 3)

Among all students, $58.78 \%$ perceived diet to influence or exacerbate acne. Most of the acne subjects used to have irregular daily meals (67.14\%) and $84.29 \%$ did not receive any kind of information from specialists, regarding the benefits of a proper diet for a healthy skin. A significant difference between the frequencies of two groups was not-

Table I. Association between the analyzed factors and the odds of acne occurrence in $N=148$ cases ( $n=70 / a c n e$ group $+n=78 /$ control group).

\begin{tabular}{|c|c|c|c|c|c|c|}
\hline \multirow{3}{*}{ Exposure factor } & & \multicolumn{2}{|c|}{$\begin{array}{l}\text { Adolescent group / } \\
\text { Number of cases }\end{array}$} & \multicolumn{3}{|c|}{$\begin{array}{c}\text { Statistical parameter / } \\
\text { Calculated value and significance }\end{array}$} \\
\hline & & Control & Acne & \multirow[b]{2}{*}{ OR } & \multirow[b]{2}{*}{$95 \% \mathrm{Cl}$} & \multirow[b]{2}{*}{$P$} \\
\hline & & $\mathrm{n}=78$ & $\mathrm{n}=70$ & & & \\
\hline Family history & Yes & 17 & 40 & $4.784^{\star}$ & $2.337-9.794^{\star \star}$ & $<0.001^{*}$ \\
\hline Environment & Urban & 59 & 42 & $0.483^{\star \star}$ & $0.239-0.977^{\star}$ & $0.041^{*}$ \\
\hline Body Mass Index $\geq 25$ & Overweight/obese & 5 & 16 & $4.326^{\star}$ & $1.492-12.54^{\star \star}$ & $0.004^{\star}$ \\
\hline Smoking habits & Yes & 29 & 44 & $2.859^{\star}$ & $1.467-5.576^{\star \star}$ & $0.002^{\star}$ \\
\hline Dietary habits & Irregular schedule & 23 & 47 & $0.359^{\star \star}$ & $0.183-0.702^{\star}$ & $0.003^{*}$ \\
\hline Diet information & No & 28 & 59 & $0.104^{\star *}$ & $0.047-0.230^{\star}$ & $<0.0001^{*}$ \\
\hline Milk & $>250$ mL/day & 16 & 14 & 0.969 & $0.434-2.163$ & $0.9382^{\star \star}$ \\
\hline Yoghurt & $>150$ mL/5-6 / week & 11 & 8 & $0.786^{\star \star}$ & $0.297-2.082$ & $0.8063^{\star *}$ \\
\hline Cheese & $>150 \mathrm{~g} / 2-4 /$ week & 13 & 16 & $1.481^{*}$ & $0.655-3.351$ & $0.4088^{\star *}$ \\
\hline Sweets & $>100 \mathrm{~g} /$ day & 15 & 41 & $5.938^{\star}$ & $2.841-12.41^{\star \star}$ & $<0.0001^{*}$ \\
\hline Carbonated drinks & $>200 \mathrm{~mL} /$ freq./ daily & 16 & 46 & $7.427^{\star}$ & $3.548-15.55^{\star \star}$ & $<0.0001^{*}$ \\
\hline Dietary fats & $>100 \mathrm{~g} / 2-4 /$ week & 12 & 39 & $6.919^{\star}$ & $3.187-15.02^{\star \star}$ & $<0.0001^{\star}$ \\
\hline White bread & $>350 \mathrm{~g} /$ day & 9 & 25 & $4.259^{\star}$ & $1.821-9.962^{\star \star}$ & $0.0007^{\star}$ \\
\hline Fruits and vegetables & $250 \mathrm{~g} / 2-3 /$ day / more & 49 & 18 & $0.205^{\star \star}$ & $0.101-0.415^{\star}$ & $<0.0001^{*}$ \\
\hline Fish & $150 \mathrm{~g} / 2-4 /$ week / more & 42 & 9 & $0.126^{\star \star}$ & $0.055-0.290^{\star}$ & $<0.0001^{*}$ \\
\hline
\end{tabular}

Measure of exposure factor on acne odds: *with higher odds $(\mathrm{OR}>1)$; ** with lower odds $(\mathrm{OR}<1)$; does not affect $(\mathrm{OR}=1)$.

Estimated precision of the OR: *high level (small Cl); **low level (large Cl).

Chi-square test (acne group vs. control group): *statistically significant $(p<0.05)$; * ${ }^{*}$ statistically insignificant $(p>0.05)$. 
Table II. Association between the analyzed factors and the odds of their influence on acne severity in $N=70$ cases ( $n=32 /$ mild acne $+n=38$ / moderate or severe acne)

\begin{tabular}{|c|c|c|c|c|c|c|}
\hline \multirow{3}{*}{ Exposure factor } & & \multicolumn{2}{|c|}{ Number of cases $(n)$} & \multirow{2}{*}{\multicolumn{3}{|c|}{$\begin{array}{c}\text { Statistical parameter / } \\
\text { Calculated value and significance }\end{array}$}} \\
\hline & & \multirow[t]{2}{*}{ Mild Acne } & \multirow{2}{*}{ Moderate/ Severe Acne } & & & \\
\hline & & & & OR & $95 \% \mathrm{Cl}$ & $\mathrm{p}$ \\
\hline Family history & Yes & 16 & 24 & $1.714^{*}$ & $0.659-4.462$ & $0.2678^{\star \star}$ \\
\hline Body Mass Index $\geq 25$ & Overweight/obese & 3 & 13 & $5.027^{\star}$ & $1.284-19.682$ & $0.0210^{\star}$ \\
\hline Smoking habits & Yes & 20 & 24 & 1.029 & $0.389-2.722$ & $0.9547^{\star *}$ \\
\hline Dietary habits & Irregular schedule & 18 & 29 & $0.399^{\star \star}$ & $0.143-1.110$ & $0.1272^{\star \star}$ \\
\hline Milk & $>250 \mathrm{~mL} /$ day & 6 & 8 & $1.156^{\star}$ & $0.354-3.768$ & $0.8104^{\star *}$ \\
\hline Yoghurt & >150 mL/5-6/ week & 2 & 6 & $2.813^{*}$ & $0.526-15.037$ & $0.2752^{\star *}$ \\
\hline Cheese & $>150 \mathrm{~g} / 2-4 /$ week & 5 & 11 & $2.200^{*}$ & $0.673-7.191$ & $0.2559^{\star *}$ \\
\hline Sweets & $>100 \mathrm{~g} /$ day & 13 & 28 & $4.092^{\star}$ & $1.491-11.233$ & $0.0107^{\star}$ \\
\hline Carbonated drinks & >200 mL/freq./ daily & 17 & 29 & $2.843^{\star}$ & $1.024-7.890$ & $0.0745^{\star \star}$ \\
\hline Dietary fats & $>100 \mathrm{~g} / 2-4 /$ week & 12 & 27 & $4.091^{*}$ & $1.502-11.144$ & $0.0049^{\star}$ \\
\hline White bread & $>350$ g/day & 8 & 17 & $2.429^{\star}$ & $0.872-6.765$ & $0.1425^{\star *}$ \\
\hline Fish & $150 \mathrm{~g} / 2-4 /$ week/ more & 6 & 3 & $0.371^{\star *}$ & $0.085-1.626$ & $0.2833^{\star *}$ \\
\hline
\end{tabular}

Measure of exposure factor on acne odds: *with higher odds $(\mathrm{OR}>1)$; ** with lower odds $(\mathrm{OR}<1)$; does not affect $(\mathrm{OR}=1)$.

Chi-square test (moderate/severe acne vs. mild acne): *statistically significant $(p<0.05) ;{ }^{* *}$ statistically insignificant $(p>0.05)$.

ed $(\mathrm{p}<0.05)$, but according with OR and CI values, these variables were not risk factors for acne development.

With respect to dairy products, an intake of milk $250 \mathrm{ml} /$ day, yoghurt $-150 \mathrm{gr} / 5-6$ times weekly and cheese (various types) $-150 \mathrm{gr} / 2-4$ times weekly was considered as standard. Comparing the two groups, no major difference was observed: excessive milk consumption was almost similar among the subjects of two groups, $20.51 \%$ for healthy subjects, respectively $20.0 \%$ for acne subjects. The percentage of subjects that reported an increased intake of yoghurt was slightly higher for control group compared with acne group ( $14.10 \%$ and $11.43 \%$, respectively). In turn, an increased consumption of cheese was reported by more subjects belonging to acne group than healthy group $(22.86 \%$ and $16.67 \%$, respectively). Statistical analysis showed that dairy products were not risk factors for acne occurrence.

Considering the high glycemic index of sweets and carbonated drinks, the influence of an excessive consumption (more than $100 \mathrm{gr} /$ day sweets and frequently or daily consumption of $200 \mathrm{ml}$ carbonated drinks) has been evaluated. Among the acne group was recorded a much higher percentage of subjects reporting an excessive consumption of above food categories than control group $58.57 \%$ and $19.23 \%$ for sweets; $65.71 \%$ and $20.51 \%$ for carbonated drinks). In the category of dietary fats represented by saturated fats from processed meat (ham, hamburger, hot dog, sausages or others) we considered a normal intake for adolescents of $100 \mathrm{~g}$ 2-3 times maximum per week. $55.71 \%$

\begin{tabular}{|c|}
\hline Lifestyle Exposure Factor/Acne Occurence \\
(self questioned method: $n=148$ total)
\end{tabular}

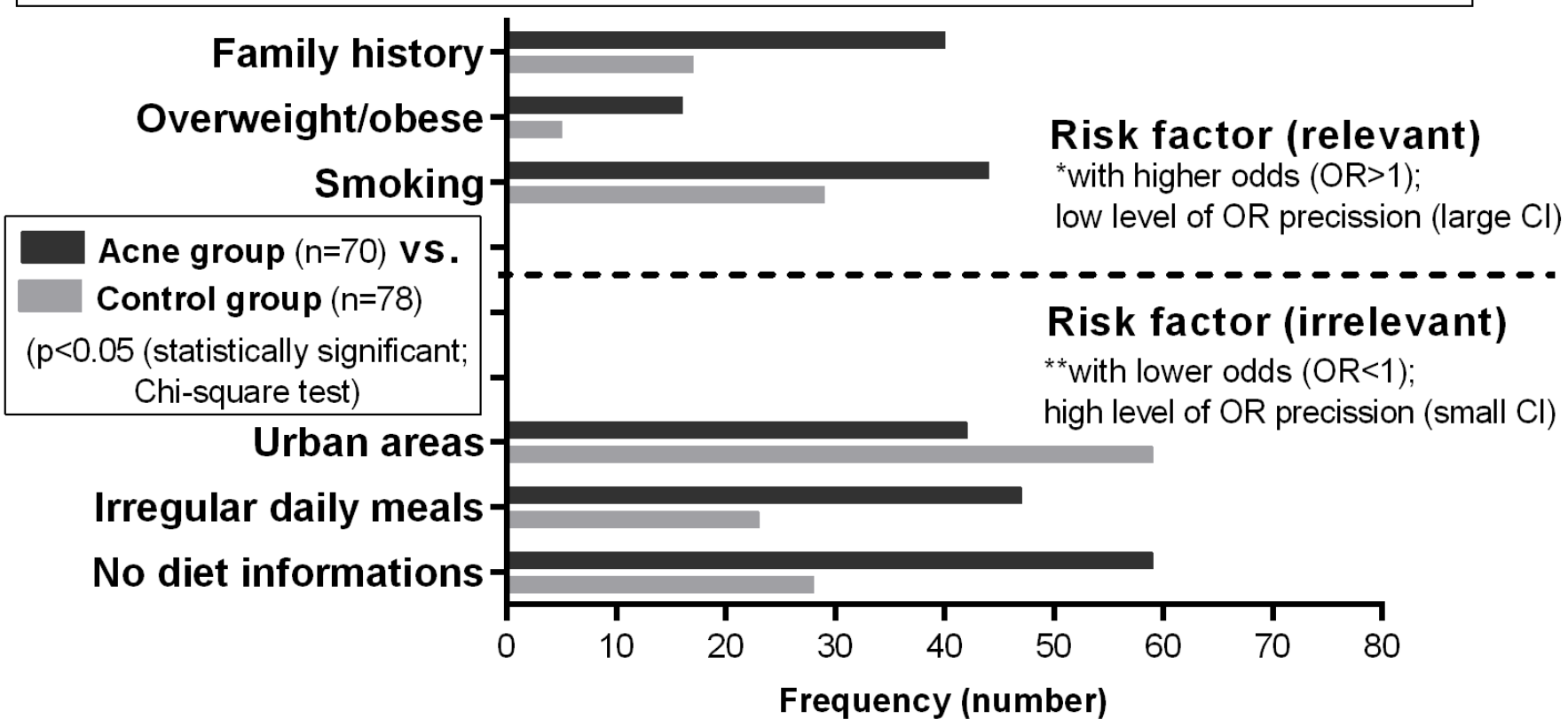

Fig. 2. Analysis of acne occurence depending on the lifestyle factors 
Dietary Exposure Factor/Acne Occurence

(self questioned method: $n=148$ total)

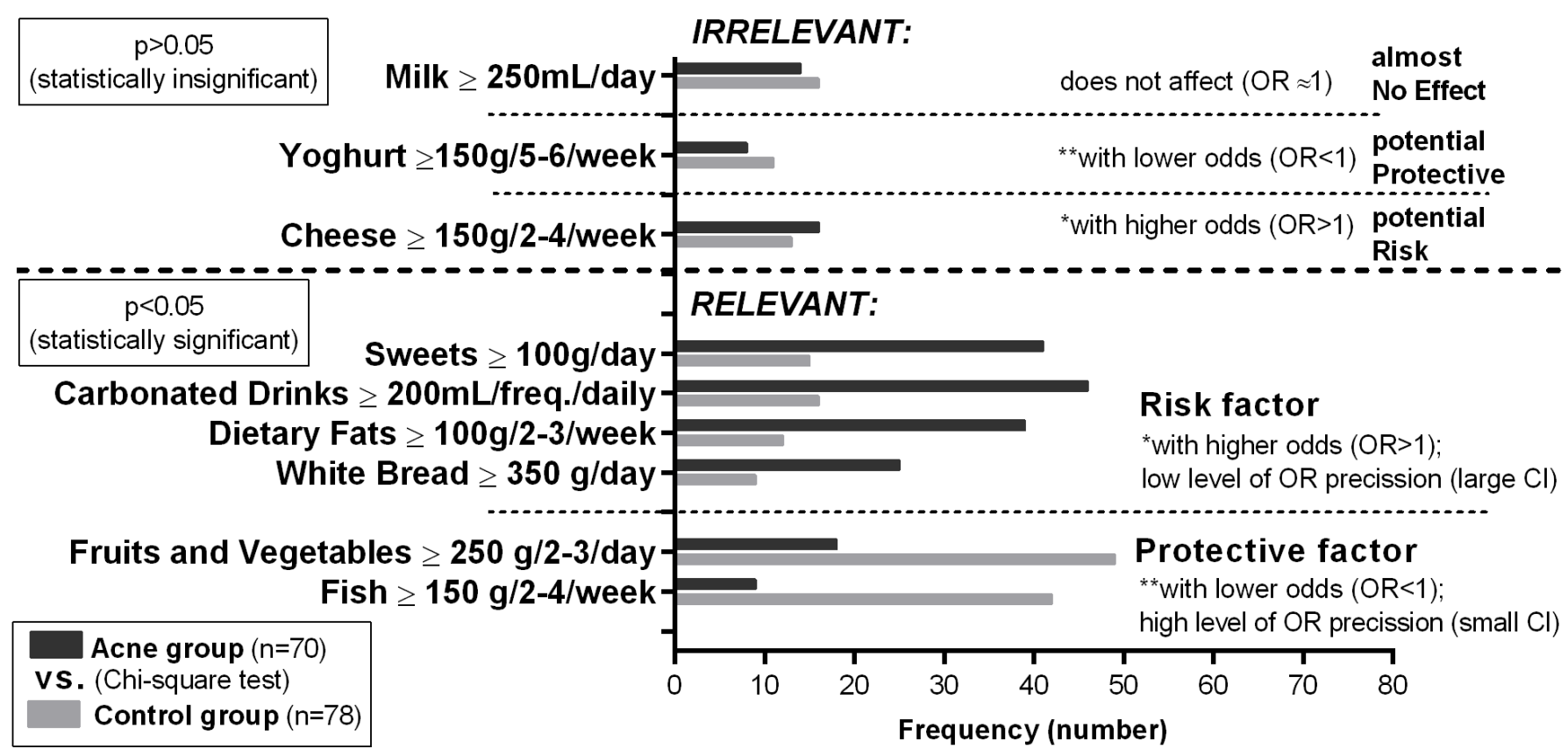

Fig. 3. Analysis of acne occurence depending on the dietary factors

of acne subjects reported an increased weekly intake of dietary fats, while $43.59 \%$ of control group reported a lower consumption than normal, or even they never have processed meat. Only $15.38 \%$ of healthy subjects reported an excessive intake of dietary fats. Considering the high glycemic index for white bread compared with whole-wheat bread, was noticed that only 9 participants belonging to acne group were consuming whole-wheat bread instead of white bread, and $35.7 \%$ reported an excessive intake of white bread. In the control group, the percentage of subjects consuming whole-wheat bread was higher (24.4\%), and only 9 subjects reported an increased intake of white bread. As it was found a statistically significant difference between the two groups concerning their excessive intake of sweets, carbonated drinks, dietary fats and white bread, these dietary factors have been considered as risk factors for acne occurrence.

The influence of studied dietary protective factors on acne occurrence (Figure4)

$53.85 \%$ of healthy subjects reported a normal or increased weekly intake of fish meat (150g / 2-4 times per week), while only $12.86 \%$ of subjects belonging to the acne group reported similar consumption. The most of them, $87.14 \%$ reported that they never or hardly ever consume fish. Regarding the recommended intake of $250 \mathrm{~g}$ of fruits and vegetables $2-3$ times daily, $74.29 \%$ of acne group subjects reported a lower consumption than recommended, while $62.8 \%$ of control group reported a normal or even higher intake of fruits and vegetables.
A significant negative correlation between a normal or higher intake of fish, vegetables, fruits and acne prevalence was observed. According with statistical analysis $(p<0.0001)$, our results showed a protective effect of these foodstuffs on acne vulgaris development.

The influence of the studied risk factors on acne severity (Figure 5)

No differences were found as regard to family history, living environment, smoking, dietary habits, lack of nutritional information and dairy products consumption. Significant differences were observed in meaning that a higher

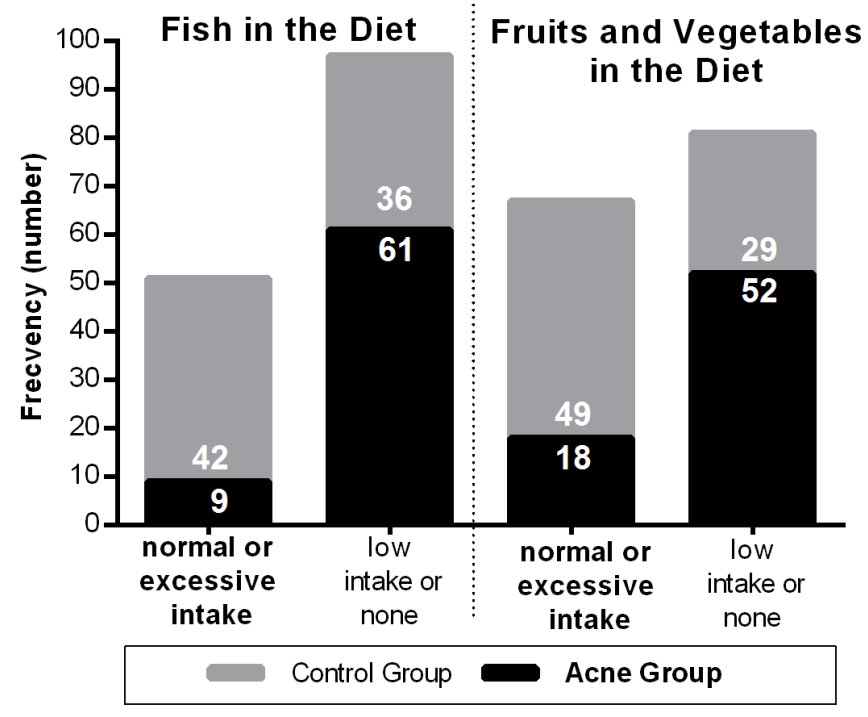

Fig. 4. Acne-protective factors as frequency in the adolescences' dietary habits 


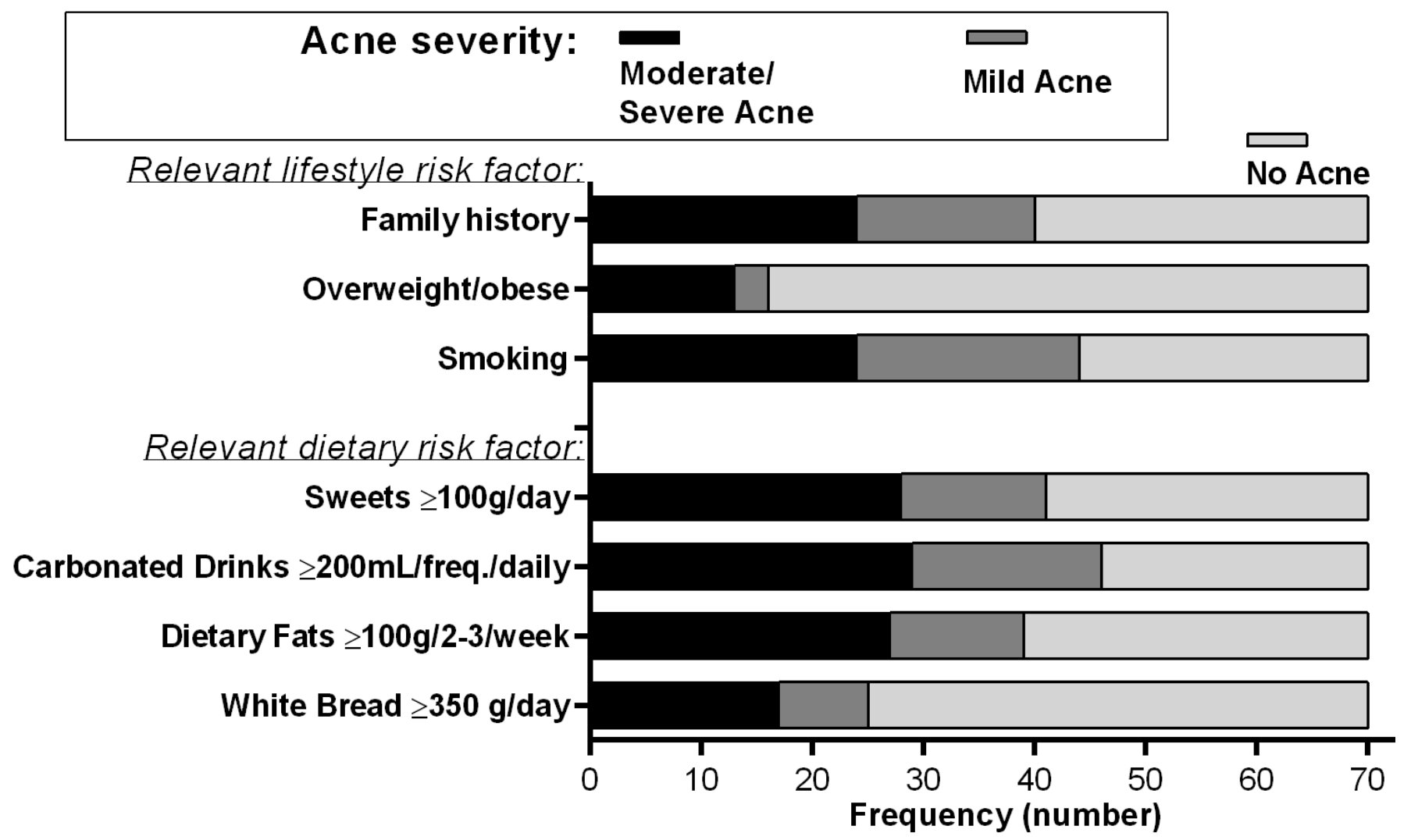

Fig. 5. Analysis of acne severity depending on the associated risk factors

percentage of subjects with moderate/severe acne were overweight or obese than those with mild acne (18.57\% and $4.29 \%$, respectively). Likewise, an excessive intake of sweets ( $40.0 \%$ vs. $18.57 \%)$, carbonated drinks $(41.43 \%$ vs. $24.29 \%)$, dietary fats $(38.57 \%$ vs. $17.14 \%)$ and white bread $(24.29 \%$ vs. $11.43 \%)$ was more frequent among the subjects with moderate/severe acne than those with mild acne.

The influence of the studied protective factors on acne severity (Figure 6)

Both the frequency of a low intake of fish $(50.0 \%$ vs. $37.14 \%)$ as well as a low consumption of vegetables and fruits ( $47.14 \%$ vs. $27.14 \%$ ) were found higher in the moderate/severe acne subjects than the mild acne group.

\section{Healthy lifestyle education level}

The results suggest that majority of the surveyed adolescents $(84.29 \%)$ had no basic knowledge about the negative effects of an unhealthy lifestyle on skin health, neither from health professionals and nor from school or families.

\section{Comparative analysis of our data with the previously reported}

Acne prevalence in adolescents: So far, has been suggested that acne prevalence varies depending on ethnicity, geographic area and the system used to evaluate the severity degree, leading to the conclusion that besides hormonal and genetic causes of acne, there are a lot of factors that may play an important role in acne pathogenesis, like environmental factors, nutrition, smoking, hygienic habits. Most studies have shown a prevalence of acne between 60-90\%, being more frequent in males among teenagers, and females among adults. In 2009, Ghodsi et al found among pupils aged $16 \pm 0.9$ years a prevalence of $92-94.4 \%$, of which $14 \%$ were moderate to severe acne [28]. In 2012, in a community-based study conducted by Shen et al in six Chinese cities (mean age 41.8 years), acne prevalence was found of $46.8 \%$ in the 19 years group, the overall prevalence of mild acne being of $68.4 \%$, moderate acne $26.0 \%$ and severe acne $5.6 \%$ [29]. In a survey study performed in

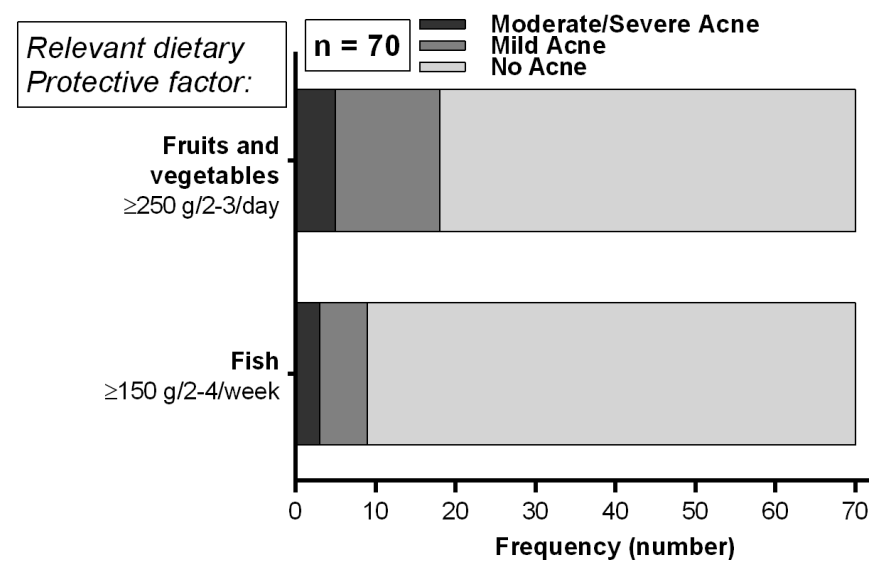

Fig. 6. Analysis of acne severity depending on the associated protective factors 
2004 in New Zeeland by Purvis et al on a secondary school students group, $67.3 \%$ of students were reported as having acne. But the authors used in this case only a self-reported acne questionnaire, without subjects' clinical examination [30]. In our study, an overall acne prevalence of $47.3 \%$ (fig.1) was found, affecting $37.84 \%$ of males and $9.46 \%$ of female subjects. The low value of prevalence among females was probably due to the specific conditions of the high school, $74.32 \%$ of the students enrolled in eleventh and twelfth grade being males. Our results with respect to acne prevalence are similar with that obtained by Shen (2012), but our research was performed on a single community of teenagers, which is in fact, a limitation of the presented study.

Possible associated factors which can affect the odds of acne occurrence: In order to evaluate the influence of various lifestyle factors on acne vulgaris occurence (fig.2), the data reported in our study by the subjects diagnosed with acne (acne group) were compared with those reported by the healthy subjects (control group).

-Family history: Our results suggested that family history of acne was significantly more frequent in subjects with acne than in healthy subjects, a finding that is in accordance with Di Landro (2012) and Ghodsi (2009) results $[31,28]$. Moreover, Di Landro suggested that acne vulgaris is associated with a family history of acne in first degree relatives, mother and father [31]. Ghodsi noticed that acne prevalence was influenced more by the mother acne history than by that of father's, brothers' or sisters', and in the same time, acne prevalence was higher for subjects with a greater number of family members affected by acne [28]. Another limitation of our study was that we haven't done a differentiation between first degree relatives, namely mother, father, brothers or sisters, and also we didn't evaluate the impact of an increased number of family members with acne.

-An overweight or obese status: is usually correlated with an unhealthy eating behavior, including increased intake of high dietary fats and high glycemic index food. Similar with Di Landro et al (2012), our results suggest an elevated risk of acne vulgaris development for the subjects with a higher Body Mass Index (BMI) [31]. Contrary, Wolkenstein et al reported (also in 2012) that acne severity was not associated with BMI [32]. In our results, a BMI value $\geq 25$ leaded to a significant effect on acne occurrence, but this finding had a low degree of precision by the OR/CI calculation method. Given these findings, the influence of an overweight or obese status on acne vulgaris development should be further explored.

-The smoking habit: In 2009 and 2010, Capitanio et al suggested that a new clinical form of acne, characterized by retention lesions and few inflammatory lesions, termed by authors as "comedonal post-adolescent acne", appeared to be the most frequent clinical form among females 25-50 years, being strictly correlated with smoking habits $[33,34]$. In a similar study to ours, performed in 2012 by Wolkenstein et al, but on a larger sample of French people and a wider age range, 15-69 years, they noted that smoking was associated with acne severity [32]. In contrast with Ghodsi et al results [28], that reported in 2009 no correlation between acne severity and smoking, Klaz et al (2006), based on a cohort study on a large group of young male subjects $(n=27,083)$, suggested an inverse association between smoking and acne vulgaris severity [35]. Even though our study highlighted a greater frequency of smokers among the acne group, a clear relationship between smoking and acne has not been established because we couldn't evaluate if the participants started smoking after the onset of acne or as a consequence of acne. Therefore, further investigations to clarify the mechanism of action by which smoking can influence or not acne vulgaris occurrence and aggravation are needed.

-Living environment: It is well-known that living in urban areas is usually correlated with a westernized diet consisting mainly of high glycemic load food; also, among the adolescents, an unhealthy eating behavior is very common, most of them using to have an irregular daily meals schedule. Cordain et al, in their investigation performed in 2002 on 1315 subjects living in non-westernized areas (1200 Kitavan subjects from Papua New Guinea and 115 Ache subjects from Paraguay) using to have traditional diets based on vegetables and animal food minimally processed, reported no case of acne in both population [36]. In our study, a significant higher frequency of subjects living in urban areas was observed for the both groups and also, a higher frequency of subjects belonging to acne group that used to have an irregular eating schedule. But, some of the participants coming from rural areas, used to live different periods of time in the city of Tg-Mures. This fact should be taken into account as a possible source of errors.

-Diet lifestyle and dietary compounds: The influence of excessive consumption of dairy products on acne vulgaris is still controversial. Abedamowo et al performed two prospective cohort studies in 2006 and 2008, on female and male participants, aged 9-15 years, finding that acne was positively associated with an increased consumption of total milk, whole milk, low fat milk and skim milk for females and total milk, skim milk for males. The limitation was that they couldn't distinguish trend between low-fat and whole milk [37,38]. In turn, many years earlier, in 1971 in a case series study, Anderson reported no increases in acne lesions with the consumption of chocolate, milk and cola [39]. In our investigation (fig.3), was not found an association between acne risk and an increased consumption of milk, yoghurt and cheese. A limitation of our study is that we didn't distinguish between milk categories, the majority of participants reporting whole milk consumption.

Similar with our study, Law et al in their cross-sectional study performed in 2009 on 322 participants aged 17.420.8 years, reported negatively association between dairy consumption and acne occurrence [40]. Although most studies conducted to date claim milk as the main factor that aggravates acne, there are still insufficient data to rec- 
ommend restricting milk consumption in acne treatment. Further randomized controlled trials are necessary to evaluate the association between dairy products and acne vulgaris.

Risk factors associated with acne occurrence and severity: The high glycemic index food as sweets, carbonated drinks including beer, dietary fats and white bread are rapidly absorbed. An excessive intake leads to a high level of serum glucose and consequently to hyperinsulinemia, increased IGF-1, suppressed SHBG, elevated androgens and sebum production, their role being well-known in acne pathogenesis [41]. Earlier studies conducted by Grant et al [42] and Fulton et al [43] in 1965 and 1969, reported that chocolate consumption did not aggravate the acne severity. Even though these investigations were subject blinded interventions, they were performed on short duration of time and small sample size, with no baseline diet analysis. In 2009, Ghodsi et al performed a cross-sectional study on 1002 participants, finding that acne was positively associated with an increased consumption of sweets, chocolate and oily food [28]. Smith et al performed two randomized controlled trials in 2007 and 2008, observing that a low glycemic load diet improves acne severity, insulin sensitivity and causes changes in surface triglycerides composition $[21,44,45]$. Our study results (fig.3, fig.5) show a significant elevated risk of acne vulgaris for an excessive weekly intake of sweets, carbonated drinks, white bread and dietary fats from processed meat, statistical analysis suggesting that all these dietary variables were risk factors for acne occurrence and severity.

Dietary protective factors associated with acne occurrence and severity:

-Fruits and vegetables intake: Regarding the necessary weekly intake of fruits and vegetables, all nutrition guides recommend a minimum intake of $150-250$ gr 2-3 times per day. In a cross-sectional study on 3775 participants from Norway, aged between 18-19 years, Halvorsen et al found in 2009 that acne is negatively associated with frequent vegetables consumption among female participants [46]. In a similar study performed in 2010 by Wei et al in China, on 5696 participants aged 17-25 years, the authors reported a positively correlation between acne and high fat diet, and a negatively association with frequent fruits consumption [47]. Similar with these authors, in our investigation (fig.4, fig.6) was noticed an inverse correlation between acne vulgaris development and severity and the consumption of fruits and vegetables.

-Fish as dietary intake: Regarding the influence of various lifestyle factors on acne severity, Rietkerk and Woolf (2014) in their investigation, observed that participants with moderate and severe acne had fewer servings of fish per day than those with mild or no acne [48]. Similar with Di Landro et al (2012) [31], our results (fig.4, fig.6) demonstrated an inverse association between excessive fish consumption and acne occurrence and severity.

\section{Conclusions}

Family history, smoking behavior, excessive dietary fats, sweets, carbonated drinks and white bread could be considered as risk factors in acne vulgaris. Along with the prior referred factors, obesity condition may lead to disease's aggravation. An increased weekly intake of fish, vegetables and fruits, may have a protective effect in acne development or severity. The influence of living environment and dietary habits should be further investigated. A better education among adolescents especially regarding the benefits of a healthy lifestyle for a healthier skin is required.

\section{Acknowledgments}

This paper is supported by the Sectoral Operational Programme Human Resources Development (SOP HRD), financed from the European Social Fund and by the Romanian Government under the contract number POSDRU/159/1.5/S/137390/

\section{Conflict of interest}

None to declare.

\section{References}

1. Barkley LD. Acne, its Etiology, Pathology and Treatment. New York, NY: GP Putnam's Sons. 1885.

2. Koo J. The psychosocial impact of acne: patients' perceptions. J Am Acad Dermatol. 1995;32:S26-S30.

3. Tan J, Vasey K, Fung K. Beliefs and perceptions of patients with acne. J Am Acad Dermatol. 2001;44:439-445.

4. Koldovsky O. Hormones in milk. Vitam Horm. 1995;50:77-149.

5. Chen W, Thiboutot D, Zouboulis CC. Cutaneous androgen metabolism: basic research and clinical perspectives. J Invest Dermatol. 2002;119:992-1007.

6. Rosenfield R. Ovarian and adrenal function in polycystic ovary syndrome. Endocrinol Metab Clin North Am. 1999;28:265-293.

7. Rosenfield R. Polycystic ovary syndrome and insulin resistant hyperinsulinemia. J Am Acad Dermatol. 2001;45:S95-S104.

8. Davidovici BB, Wolf $\mathrm{R}$. The role of diet in acne: facts and controversies. Clin Dermatol. 2010;28:12-16.

9. Hoyt G, Hickey MS, Cordain L. Dissociation of the glycaemic and insulinaemic responses to whole and skimmed milk. $\mathrm{Br} J$ Nutr. 2005;93(2):175-177

10. Hoppe C, Molgaard C, Michaelsen KF. Cow's milk and linear growth in industrialized and developing countries. Annu Rev Nutr. 2006;26:131173.

11. Melnik BC. Evidence for acne-promoting effects of milk and other insulinotrophic dairy products. Nestle Nutr Workshop Ser Pediatr Program. 2011;67:131-145.

12. Burris J, Rietkerk, Woolf K. Acne: The Role of Medical Nutrition Therapy. J Acad Nutr Diet. 2013;113:416-430.

13. Melnik BC. Dietary intervention in acne: Attenuation of increased mTORC1 signaling promoted by Western diet. Dermatoendocrinol. 2012;1:20-32.

14. Melnik BC, Schmitz G. Role of insulin, insulin-like growth factor-1, hyperglycemic food and milk consumption in the pathogenesis of acne vulgaris. Exp Dermatol. 2009;18:833-841.

15. Smith TM, Gilliland K, Clawson GA, Thiboutot D. IGF-1 induces SREBP-1 expression and lipogenesis in SEB-1 sebocytes via activation of the phosphoinositide 3-kinase/Akt pathway. J Invest Dermatol. 2008; 128:1286-1293.

16. Crave JC, Lejeune H, Brebant C, Baret C, Pugeat M. Differential effects of insulin and insulin-like growth factor-1 on the production of plasma steroid-binding globulins by human hepatoblastoma-derived (Hep G2) cells. J Clin Endocrinol Metab. 1995;8:1283-1289.

17. Ben-Amitiai D, Laron Z. Effect of insulin-like growth factor-1 deficiency or administration on the occurrence of acne. J Eur Acad Dermatol. 2011;25:950-954.

18. Liu B, Lee HY, Weinzimer SA et al. Direct functional interaction between insulin-like growth factor-binding protein-3 and retinoid $X$ receptor- 
alpha regulate transcriptional signaling and apoptosis. J Biol Chem. 2000;275:33607-33613.

19. Vora S, Ovhal A, Jerajani H, Nair N, Chakrabortty A. Correlation of facial sebum to serum insulin-like growth factor-1 in patients with acne. $\mathrm{Br} J$ Dermatol. 2008;159:990-991.

20. Pappas A, Anthonavage M, Gordon J. Metabolic fate and selective utilization of major fatty acids in human sebaceous gland. J Invest Dermatol. 2002;118:164-171.

21. Wolf R, Matz H, Orion E. Acne and Diet. Clin Dermatol. 2004;22:387393.

22. Lewis RA, Austen KF, Soberman RJ. Leukotrienes and other products of the 5-lipoxygenase pathway. Biochemistry and relation to pathobiology in human diseases. N Engl J Med. 1990;323:645-655.

23. Zouboulis $\mathrm{CHC}$, Saborowski A, Boschnakow A. Zileuton, an ora 5-lipoxygenase inhibitor, directly reduces sebum production. Dermatology. 2005;210:36-38.

24. Gannon MC, Nuttall FQ, Westphal SA, Seaquist ER. The effect of fat and carbohydrate on plasma glucose, insulin, C-peptide and triglycerides in normal male subjects. J Am Coll Nutr. 1993;12:36-41.

25. Bhathena SJ, Berlin E, Judd JT et al. Effects of omega 3 fatty acids and vitamin $\mathrm{E}$ on hormones involved in carbohydrate and lipid metabolism in men. Dermatology. 1991;54:684-688.

26. Li Y, Seifert MF, Ney DM et al. Dietary conjugated linolenic acids alter serum IGF-1 and IGF binding protein concentrations and reduce bone formation in rats fed (n-6) or (n-3) fatty acids. J Bone Miner Res. 1999;14:1153-1162

27. Szumilas M. Explaining Odds Ratios. J Can Acad Child Adolesc Psychiatry. 2010;19: 227-229.

28. Ghodsi SZ, Orawa H, Zouboulis CC. Prevalence, severity, and severity risk factors of acne in high school pupils: a community-based study. J Invest Dermatol. 2009;129:2136-2141.

29. Shen Y, Wang T, Zhou C, et al. Prevalence of acne vulgaris in Chinese adolescents and adults: a community-based study of 17,345 subjects in six cities. Acta Derm Venereol. 2012;92:40-44.

30. Purvis D, Robinson E, Watson P. Acne prevalence in secondary students and their perceived difficulty in accessing acne treatment. $\mathrm{N} Z \mathrm{M}$ Med J. 2004;117:1-8.

31. Di Landro A, Cazzaniga S, Parazzini F, et al. Family history, body mass index, selected dietary factors, menstrual history, and risk of moderate to severe acne in adolescents and young adults. J Am Acad Dermatol. 2012;67:1129-1135.

32. Wolkenstein P, Misery L, Amici JM et al. PSS4 Acne and Lifestyle: Results of a Survey on a Representative Sample of the French Population. Value in Health. 2012;15:A568.

33. Capitanio B, Sinagra JL, Ottaviani $M$ et al. Acne and smoking. Dermatoendocrinol. 2009;1:129-135.

34. Capitanio B, Sinagra JL, Bordignon V et al. Underestimated clinical features of postadolescent acne. J Am Acad Dermatol. 2010;63:782788.

35. Klaz I, Kochba I, Shohat T, Zarka S, Brenner S. Severe Acne Vulgaris and Tobacco Smoking in Young Men. Journal of Investigative Dermatology. 2006;126:1749-1752.

36. Cordain L, Lindeberg S, Hurtado M et al. Acne vulgaris: a disease of Western civilization. Arch Dermatol. 2002;138:1584-1590.

37. Abedamowo CA, Spiegelman D, Berkey CS et al. Milk consumption and acne in adolescent girls. Dermatol Online J. 2006;12:1.

38. Abedamowo CA, Spiegelman D, Berkey CS et al. Milk consumption and acne in teenaged boys. J Am Acad Dermatol. 2008;58:787-793.

39. Anderson PC. Foods as the cause of acne. Am Fam Physician. 1971;3:102-103.

40. Law M, Chuh A, Molinari N, Lee A. An investigation of the association between diet and occurrence of acne: A rational approach from a traditional Chinese medicine perspective. Clin Exper Dermatol. 2009;35:31-35

41. Katta R, Desai SP. Diet and Dermatology.The Role of Dietary Intervention in Skin Disease. J Clin Aesthet Dermatol. 2014;7:46-51.

42. Grant JD, Anderson PC. Chocolate as a cause of acne: A dissenting view. Missouri Med. 1965;62:459-460.

43. Fulton J, Plewig G, Kligman A. Effect of chocolate on acne vulgaris. JAMA. 1969;210:2071-2074

44. Smith RN, Mann NJ, Braue A et al. A low-glycemic-load diet improves symptoms in acne vulgaris patients: a randomized controlled trial. Am J Clin Nutr. 2007;86:107-115.

45. Smith RN, Braue A, Varigos GA et al. The effect of a low glycemic load diet on acne vulgaris and the fatty acid composition of skin surface triglycerides. J Dermatol Sci. 2008;50:41-52.

46. Halvorsen JA, Dalgard F, Thoresen M, Bjertness E, Lien L. Is the association between acne and mental distress influenced by diet? Results from a cross-sectional population study among 3775 late adolescents in Oslo, Norway. BMC Public Health. 2009;9:340.

47. Wei B, Pang Y, Zhu H et al. The epidemiology of adolescent acne in North East China. J Eur Acad Dermatol. 2010;24:953-957.

48. Rietkerk JW, Woolf K. Relationships of Self-Reported Dietary Factors and Perceived Acne Severity in a Cohort of New York Young Adults. J Acad Nutr Diet. 2014;114:384-392. 